Anne F. Schott - James M. Rae - Kent A. Griffith

Daniel F. Hayes · Vered Sterns • Laurence H. Baker

\title{
Combination vinorelbine and capecitabine for metastatic breast cancer using a non-body surface area dosing scheme
}

Received: 1 July 2005 / Accepted: 18 September 2005/Published online: 8 November 2005

(C) Springer-Verlag 2005

\begin{abstract}
Purpose: This study sought to determine the maximum tolerated dose of flat-dosed vinorelbine in combination with capecitabine in patients with metastatic breast cancer. At the time of study initiation, it was anticipated that vinorelbine would be developed as an oral capsule. A flat dosing scheme of both drugs was used to facilitate development of the oral regimen, and because neither drug's clearance is associated with body surface area (BSA), pharmacokinetic and pharmacogenetic endpoints were explored. Experimental Design: Capecitabine was administered orally at $3,000 \mathrm{mg} /$ day on days 1-14. The starting dose of vinorelbine was $20 \mathrm{mg}$ intravenously on days 1 and 8 of a 21 -day cycle. The vinorelbine dose was escalated until dose limiting toxicity (DLT). Vinorelbine pharmacokinetics were measured after the first dose. Patients underwent genotype analysis for polymorphisms in the CYP3A5 gene, and the erythromycin breath test (ERMBT), a phenotypic test of CYP3A enzyme activity. Results: Twenty five eligible patients were enrolled. Hematologic DLT was seen at the 50 and $45 \mathrm{mg}$ vinorelbine doses; thus the recommended dose is $40 \mathrm{mg}$ on days 1 and 8. Response
\end{abstract}

A. F. Schott · J. M. Rae · D. F. Hayes · L. H. Baker

Department of Internal Medicine,

University of Michigan Medical School,

Ann Arbor, MI, USA

L. H. Baker

Department of Pharmacology,

University of Michigan Medical School, Ann Arbor, MI, USA

V. Sterns

Johns Hopkins School of Medicine,

Sidney Kimmel Comprehensive Cancer Center,

Baltimore, MD, USA

A. F. Schott $(\bowtie) \cdot$ K. A. Griffith · J. M. Rae · D. F. Hayes Breast Oncology Program,

University of Michigan Comprehensive Cancer Center,

C349 MIB, Ann Arbor, MI 48109-0848, USA

E-mail: aschott@umich.edu

Tel.: + 1-734-6154762

Fax: + 1-734-6478792 rate was $30 \%$, and disease stabilization rate was $64 \%$ (all dose levels included). Vinorelbine clearance was not associated with ERMBT, BSA, or age. CYP3A5 genotype in this small sample did not have an obvious relationship to clearance or toxicity. Conclusions: A non-BSA based dosing scheme of capecitabine and vinorelbine is safe and efficacious. BSA did not affect vinorelbine clearance. We recommend future studies with capecitabine and/or vinorelbine to compare the safety and efficacy of flat dosed versus BSA-dosed treatment.

Keywords Clinical pharmacology

Genotype-phenotype correlations .

Phase I clinical trial · Erythromycin breath test

\section{Introduction}

The primary goals of treatment of metastatic breast cancer are: (1) to improve quality of life by palliation of symptoms, and (2) to lengthen survival. These goals are most readily met in patients with hormone-responsive tumors by the use of low-toxicity endocrine therapies. Unfortunately, approximately $30 \%$ of breast cancers are hormone receptor negative, and eventually hormoneresponsive metastatic disease becomes refractory to endocrine manipulations. In hormone-refractory patients, combination chemotherapy results in higher response rates, longer times to progression [23], and in some studies prolonged overall survival [18], when compared to single agent therapy. Unfortunately, these benefits are often countered by increased toxicity and complexity of the regimen [16]. An effective combination chemotherapy regimen that is both simple and has low toxicity would be of value.

Vinorelbine has been examined in combination with 3-5 day infusions of fluorouracil in advanced breast cancer [6-9]. This combination has been well tolerated, with response rates from $47-62 \%$ (both first line and previously treated patients) [6-9]. However, continuous 
infusions of 5-fluorouracil are inconvenient due to the need for a portable infusion pump and permanent venous access devices. Daily oral administration of chemotherapeutic agents is much more convenient for patients. Capecitabine, a nucleoside prodrug of 5-fluorouracil with excellent oral bioavailability, is active in patients with previously treated [3] or untreated [19] metastatic breast cancer. The tolerability of vinorelbine and capecitabine as single agents, their non-overlapping toxicity profiles, and the previously demonstrated efficacy of vinorelbine combined with continuous infusion of fluorouracil makes this an attractive drug combination to evaluate further in metastatic cancer. At the time we initiated this study, it was anticipated that vinorelbine, which has an excellent bioavailability profile, was going to be developed as an oral capsule as well.

Normalizing drug doses to body surface area (BSA) is the traditional approach to oncology drug dosing, but in many cases it is not scientifically supportable [2, 20, 22]. This dosing approach has been validated for drugs formulated in vehicles that cause drug volume distribution to be similar to total blood volume (such as paclitaxel solubilized in polyoxyethylated castor oil)[24]. In these cases, BSA is possibly acting as a surrogate for drug volume of distribution (Vss), since Vss approximates total blood volume, which approximates BSA [24, 29].

It has been demonstrated that capecitabine clearance is unrelated to BSA [2, 4].Variability in capecitabine pharmacokinetics is likely to be primarily due to variability in the activity of the enzymes involved in capecitabine metabolism, and not body size [21]. Likewise, clearance of drugs primarily metabolized by the liver, such as vinorelbine, is not correlated with BSA [22]. Plasma clearance of vinorelbine is high, approaching hepatic blood flow in humans, and its volume of distribution is large, indicating extensive extravascular distribution [26]. For these reasons, we hypothesized that BSA-based dosing of capecitabine and vinorelbine was unnecessary. Thus, with the goal of increasing safety and convenience, this study utilized a flat dosing scheme of both capecitabine and vinorelbine. The dose of vinorelbine was escalated based on a pharmacodynamic toxicity, myelosuppression.

The metabolism of vinorelbine has been shown to be mediated by hepatic cytochrome P450 isoenzymes in the CYP3A subfamily.[10] This subfamily plays a dominant role in the metabolism of more drugs than does any other biotransformation enzyme. However, CYP3A expression varies due to environmental stimuli (such as smoking, drug intake or diet), by disease state (such as hepatic dysfunction), and by genetic mutations. Genetic variations in the CYP3A4 gene have not been shown to be related to differences in CYP3A-dependent drug clearance. However, polymorphisms in CYP3A5 have been shown to cause variation in metabolism of such drugs as cyclosporine[17] and midazolam.[5] The mutant allele, CYP3A5*3[8] is associated with low CYP3A5 protein and this allele frequency varies from $50 \%$ in African Americans to $90 \%$ in Caucasians.[12]
As exploratory endpoints, CYP3A5 genotype analysis and vinorelbine pharmacokinetics were performed, and vinorelbine clearance was correlated with age, BSA, and the erythromycin breath test (ERMBT). The ERMBT has previously been shown to predict steady state trough blood levels of drugs which are CYP3A substrates [11]. We hypothesized that homozygosity for CYP3A 5*3 and low ERMBT would be associated with reduced clearance of vinorelbine.

\section{Patients and methods}

\section{Entry criteria}

Eligible patients had metastatic breast cancer, with measurable or evaluable disease by RECIST criteria. Karnofsky performance status was $\geq 70$, and patients had normal hematologic, renal, and hepatic function defined as ANC $>1500$, platelet count $>100 \mathrm{~K}$, calculated creatinine clearance $>60 \mathrm{ml} / \mathrm{min}$, AST/ALTPatients were excluded if they had previous treatment with continuous infusion or daily oral administration of fluorouracil, capecitabine, or vinca alkaloids and if they had baseline Grade 2 or greater peripheral neuropathy, or if they were pregnant or nursing. Patients who required concurrent treatment within 7 days prior to initial vinorelbine with drugs known to induce or inhibit CYP3A activity were also ineligible. Excluded drugs included midazolam, anti-mycotic agents (ketoconazole and related compounds), macrolide antibiotics (erythromycin and related compounds), nifedipine, anti-seizure drugs, H2 blockers, grapefruit juice, and rifampin.All patients signed an informed consent regarding the experimental nature of this therapy after approval by the University of Michigan Institutional Review Board and in accordance with an assurance filed with and approved by the Department of Health and Human Services.

\section{Treatment plan}

This study was a Phase I/II study of the combination of oral capecitabine and weekly intravenous vinorelbine. Eligible patients were identified from the patient population of the University of Michigan Health System.

Both agents were given flat doses regardless of BSA. All chemotherapy was delivered on a 21-day cycle. Capecitabine was administered orally at $1,500 \mathrm{mg}$ twice daily $(3000 \mathrm{mg} /$ day $)$ on days $1-14$. The starting dose of vinorelbine was $20 \mathrm{mg}$ administered intravenously weekly on days 1 and 8 . The dose was escalated in $10 \mathrm{mg}$ increments until dose limiting toxicity (DLT), which was defined as Grade 3 or 4 toxicities (non-hematologic), or Grade 3 or 4 thrombocytopenia at any time during the first cycle. Neutropenia was considered dose-limiting if it reached Grade 3 or 4 on day 21 in the first cycle. Once DLT was defined, an intermediate dose level $(-5 \mathrm{mg})$ 
was tested, and if more than one-sixth of the patients had DLT, the next lower dose level was used. The recommended Phase II dose was the dose at which one of six or fewer patients experienced DLT. Subsequently, eight additional patients were treated at the Phase II dose in order to increase the sample size for secondary analyses.

Prior to study treatment, the ERMBT was administered in the outpatient setting within 2 weeks of the first dose of vinorelbine, performed as previously described.[27] Patients had blood drawn for pharmacokinetic analysis after the first administration of vinorelbine. Blood was collected before infusion, immediately at the end of infusion, and at 20,45, 75 min after infusion, then at 2, 3, 4, 6, 8 12, 24, 36, 48, and $72 \mathrm{~h}$. Blood samples were analyzed for vinorelbine with a liquid chromatography with mass spectrometry method as described previously.[25] Pharmacokinetic parameters were calculated using standard non-compartmental methods.

\section{CYP3A5 Genotype determination}

DNA was extracted from whole blood using the Qiagen DNeasy ${ }^{\circledR}$ Tissue kit and the QIAamp ${ }^{\circledR}$ DNA Blood Midi kit (Qiagen Inc., Valencia, CA, USA), respectively, according the manufacture's instructions and the yield was determined by spectrophotometry (Beckman DU 640; Beckman Coulter, Inc., Fullerton, CA, USA). DNA samples were assayed for the common CYP3A5*3 genetic polymorphism using polymerase chain reactionrestriction fragment length polymorphism (PCR-RFLP) assay as described previously [9].

\section{Results}

Dose escalation and toxicity

A total of 25 eligible patients were enrolled; all were Caucasian with 24 females and 1 male. Patient characteristics are described in Table 1 . The flat-dosed capecitabine was well tolerated, as there were no instances of Grade 3 hand-foot syndrome or diarrhea. Three

Table 1 Patient characteristics

\begin{tabular}{ll}
\hline Number of eligible patients & 25 \\
Average patient age (years) & $50(29-69)$ \\
Number with measurable disease & $20(80 \%)$ \\
Number: prior chemotherapies for metastatic disease & \\
0 & $10(40 \%)$ \\
1 & $12(48 \%)$ \\
2 & $3(12 \%)$ \\
Prior anthracycline & $23(92 \%)$ \\
Prior taxane & $25(100 \%)$ \\
Hormone receptor status & \\
Positive & $16(64 \%)$ \\
Negative & $9(36 \%)$ \\
\hline
\end{tabular}

patients had a dose reduction for Grade 2 capecitabine toxicity, including hand-foot syndrome and diarrhea. There was no apparent relationship between BSA and necessity for dose reduction of capecitabine.

The vinorelbine dose was escalated as described in Table 2. All 25 patients completed at least two cycles of treatment, and no patient discontinued therapy due to toxicity. Three patients were treated at the 20,30 , and $40 \mathrm{mg}$ dose levels with no DLT. At both the $50 \mathrm{mg}$ and $45 \mathrm{mg}$ dose levels, there were two hematologic DLTs (Table 2).

\section{Efficacy}

Twenty of $25(80 \%)$ patients had disease that was measurable by RECIST criteria. Overall, six of the patients with measurable disease responded [30, 95\% CI (11.9-54.3)], with one complete response. Nine of 25 patients progressed within the first 12 weeks of treatment $(36,95 \%$ CI $[18.0-57.5])$, and the remaining 16 patients had stable disease or better for over 12 weeks, with a clinical benefit rate of $64,95 \%$ CI (42.5-82.0).

\section{Pharmacokinetics}

Pharmacokinetic analysis of vinorelbine was performed on the last 13 patients enrolled in the study, including 5 patients treated at $45 \mathrm{mg} /$ week, and 8 patients treated at $40 \mathrm{mg} /$ week. The mean vinorelbine clearance of the

Table 2 Genotype, ERMBT, body surface area (BSA), and dose limiting toxicity (DLT)

\begin{tabular}{llllll}
\hline Patient & Genotype & ERMBT & $\begin{array}{l}\text { BSA } \\
\left(\mathrm{m}^{2}\right)\end{array}$ & $\begin{array}{l}\text { Vinorelbine } \\
\text { dose }(\mathrm{mg})\end{array}$ & DLT \\
\hline 1 & $\mathrm{NA}$ & 3.01 & 1.69 & 20.0 & none \\
2 & $* 3 / * 3$ & 1.44 & 1.75 & 20.0 & none \\
3 & $\mathrm{wt} / * 3$ & 2.71 & 1.62 & 20.0 & none \\
4 & $* 3 / * 3$ & 2.83 & 1.90 & 30.0 & none \\
5 & $\mathrm{wt} / * 3$ & 2.89 & 1.73 & 30.0 & none \\
6 & $* 3 / * 3$ & 3.74 & 1.65 & 30.0 & none \\
7 & $\mathrm{wt} / * 3$ & 3.09 & 1.59 & 40.0 & none \\
8 & $\mathrm{wt} / * 3$ & 1.58 & 2.40 & 40.0 & none \\
9 & $* 3 / * 3$ & 3.48 & 1.99 & 40.0 & none \\
10 & $* 3 / * 3$ & 3.81 & 1.75 & 50.0 & Low ANC \\
11 & $* 3 / * 3$ & 4.19 & 2.03 & 50.0 & none \\
12 & $* 3 / * 3$ & 1.77 & 1.78 & 50.0 & Low ANC \\
13 & $* 3 / * 3$ & 3.05 & 1.72 & 45.0 & none \\
14 & $\mathrm{wt} / * 3$ & 3.32 & 1.74 & 45.0 & none \\
15 & $* 3 / * 3$ & 2.35 & 1.69 & 45.0 & none \\
16 & $* 3 / * 3$ & 2.06 & 1.70 & 45.0 & Low ANC \\
17 & $* 3 / * 3$ & 2.07 & 1.78 & 45.0 & Low ANC \\
18 & $* 3 / * 3$ & 2.75 & 1.56 & 40.0 & none \\
19 & $* 3 / * 3$ & 3.03 & 1.72 & 40.0 & none \\
20 & $* 3 / * 3$ & 1.90 & 2.29 & 40.0 & none \\
21 & $* 3 / * 3$ & 2.87 & 1.60 & 40.0 & none \\
22 & $* 3 / * 3$ & 0.86 & 2.12 & 40.0 & none \\
23 & $* 3 / * 3$ & 3.15 & 1.67 & 40.0 & none \\
24 & $* 3 / * 3$ & 1.62 & 1.77 & 40.0 & none \\
25 & $* 3 / * 3$ & 2.57 & 1.60 & 40.0 & none \\
\hline & & & & &
\end{tabular}


population was $57.7 \mathrm{l} / \mathrm{h}$ (SD $12.7 \mathrm{l} / \mathrm{h})$, similar to that reported in the literature (Table 3) [13, 15, 26]. Clearance in $1 /$ hr was found to be unrelated to BSA, age, or ERMBT (Fig. 1). Vinorelbine was found to have a large volume of distribution at steady state (Vss) of 1,428 1 (SD 510 1), as previously reported. BSA showed no relationship to Vss of vinorelbine (Fig. 2).

\section{CYP3A5 genotype}

All patients were genotyped for the common CYP $3 \mathrm{~A} 5 * 3$ polymorphism. None of the patients were homozygous wild-type, while $20 \%(n=5)$ were heterozygous CYP3A $5 * 1 / * 3$ and $80 \%(n=20)$ were homozygous variant CYP3A $5 * 3 / * 3$. the results consistent with known allelic frequencies [11]. Low ERMBT result did not predict heterozygous CYP3A5 genotype (Fig. 2).

\section{Discussion}

Our data demonstrate the feasibility and safety of flat dosing of capecitabine and vinorelbine in a typical metastatic breast cancer population. For this combination therapy we recommend flat-dose capecitabine $1,500 \mathrm{mg}$ twice daily plus vinorelbine $40 \mathrm{mg}$ on day 1 and day 8 as being efficacious and tolerable. In comparison with other trials of this combination, the median BSA of our patient population was $1.74 \mathrm{~m}^{2}$, and the average per-meter-squared dose of capecitabine delivered was $1,724 \mathrm{mg} / \mathrm{m}^{2}$ on days 1-14 (range 1,250$1887 \mathrm{mg} / \mathrm{m}^{2}$ ). The recommended dose of vinorelbine in our study averages $23 \mathrm{mg} / \mathrm{m}^{2}$ on days 1 and 8 , of a 21 day cycle. Three Phase I studies of vinorelbine and capecitabine combination therapy in metastatic breast cancer have been published. Two of the studies ultimately recommended doses of capecitabine of $2,000 \mathrm{mg} /$ $\mathrm{m}^{2} / \mathrm{d}$ and vinorelbine $25 \mathrm{mg} / \mathrm{m}^{2}$ on days 1 and $8[14,28]$; the other study in elderly patients recommended capecitabine $1,250 \mathrm{mg} / \mathrm{m}^{2} / \mathrm{d}$ and vinorelbine $20 \mathrm{mg} / \mathrm{m}^{2}$ on days 1 and 8.[6]

Our patient population primarily included patients being treated first- or second-line with chemotherapy, but all had received prior taxanes and most had also received prior anthracyclines, either in the metastatic or adjuvant setting. The historical data would suggest a $20 \%-30 \%$ response rate from single agent capecitabine in this population [3, 19]. The observed $30 \%$ response rate and $65 \%$ disease stabilization rate compares favorably to the historical sample, despite the escalating doses of vinorelbine received by the patients, with minimal hematologic or non-hematologic toxicity.

The a priori hypothesis was that there would be no association between toxicity of the flat-dosed combination regimen with BSA, and this hypothesis is supported by our data. We also found no association between BSA and clearance of vinorelbine, as has been previously shown with capecitabine [4]. This is not surprising, since the impact of BSA on the variability in drug pharmacokinetics is more likely to be apparent for drugs where the distribution is similar to total blood volume (and thus to BSA).

Despite the fact the vinorelbine is largely metabolized by P450 enzymes of the CYP3A subfamily[10], there was also no association noted between the ERMBT, vinorelbine clearance, or toxicity. This observation suggests that the ERMBT would not be a useful test in tailoring the dose of vinorelbine to an individual's metabolic phenotype, in contrast to our finding in a prior study of the ERMBT and docetaxel [7].

Only five patients in our population were heterozygous for the CYP3A $5 * 3$ allele while the remainder were homozygous CYP3A5*3. The CYP3A5*3 allele codes for an aberrantly spliced mRNA with a premature stop codon, therefore, patients with two CYP $3 \mathrm{~A} 5 * 3$ alleles exhibit a nearly complete lack of CYP3A5 protein expression [11]. We hypothesized that increased vinorelbine clearance and decreased toxicity would correlate with homozygosity for the wild-type CY3A5 allele $(* 1)$ and less so with CYP3A $5 * 1 / * 3$. Since our study had $n=0$ homozygous wild-type CYP3A $5 * 1$ and only $n=5$ heterozygous CYP3A $5 * 3$ patients, the lack of any genotype/phenotype association makes a false negative result highly likely. A larger study is needed to confirm these results.
Table 3 Vinorelbine pharmacokinetics in the study population
$A U C C_{(\mathbf{0}-\infty)}$ systemic exposure; $C L$ mean plasma clearance; $C_{\max }$ maximum concentration; $T_{\max }$ time to maximum concentration; $\mathrm{t}_{1 / 2}$ terminal phase half-life; VsS volume of distribution at steady state

\begin{tabular}{llllllll}
\hline $\begin{array}{l}\text { Vinorelbine } \\
\text { dose }(\mathrm{mg})\end{array}$ & $\begin{array}{l}\mathrm{AUC}_{(0-\mathrm{t})} \\
(\mathrm{h} * \mathrm{ng} / \mathrm{ml})\end{array}$ & $\begin{array}{l}\mathrm{AUC}_{(0-\infty)} \\
(\mathrm{h} \text { ng/ml) }\end{array}$ & $\begin{array}{l}\mathrm{CL} \\
(\mathrm{l} / \mathrm{h})\end{array}$ & $\begin{array}{l}\mathrm{C}_{\max } \\
(\mathrm{ng} / \mathrm{ml})\end{array}$ & $\begin{array}{l}\mathrm{T}_{\max } \\
(\mathrm{h})\end{array}$ & $\begin{array}{l}\mathrm{T}_{1 / 2} \\
(\mathrm{~h})\end{array}$ & $\begin{array}{l}\text { Vss } \\
(\mathrm{l})\end{array}$ \\
\hline 45.0 & 900.0 & 936.1 & 48.1 & 860.6 & 0.25 & 19.1 & 876.0 \\
45.0 & 649.1 & 693.4 & 64.9 & 1000.6 & 0.15 & 31.9 & 1487.5 \\
45.0 & 604.0 & 643.8 & 69.9 & 1073.0 & 0.15 & 35.6 & 1628.5 \\
45.0 & 853.8 & 878.4 & 51.2 & 1185.8 & 0.17 & 23.6 & 885.7 \\
45.0 & 762.3 & 806.8 & 55.8 & 918.5 & 0.17 & 33.0 & 1219.8 \\
40.0 & 941.9 & 975.9 & 41.0 & 1516.7 & 0.17 & 25.2 & 744.7 \\
40.0 & 625.5 & 665.9 & 60.1 & 598.1 & 0.27 & 26.2 & 1873.8 \\
40.0 & 599.0 & 641.8 & 62.3 & 633.7 & 0.17 & 31.3 & 1553.6 \\
40.0 & 959.6 & 1002.0 & 39.9 & 965.3 & 0.18 & 25.3 & 850.2 \\
40.0 & 770.2 & 850.3 & 47.0 & 294.0 & 0.25 & 26.6 & 1330.6 \\
40.0 & 679.7 & 767.3 & 52.1 & 1410.9 & 0.18 & 53.9 & 1677.0 \\
40.0 & 395.7 & 440.7 & 90.8 & 360.8 & 0.18 & 46.6 & 2777.6 \\
40.0 & 559.5 & 602.8 & 66.4 & 670.5 & 0.18 & 31.8 & 1657.6 \\
\hline
\end{tabular}



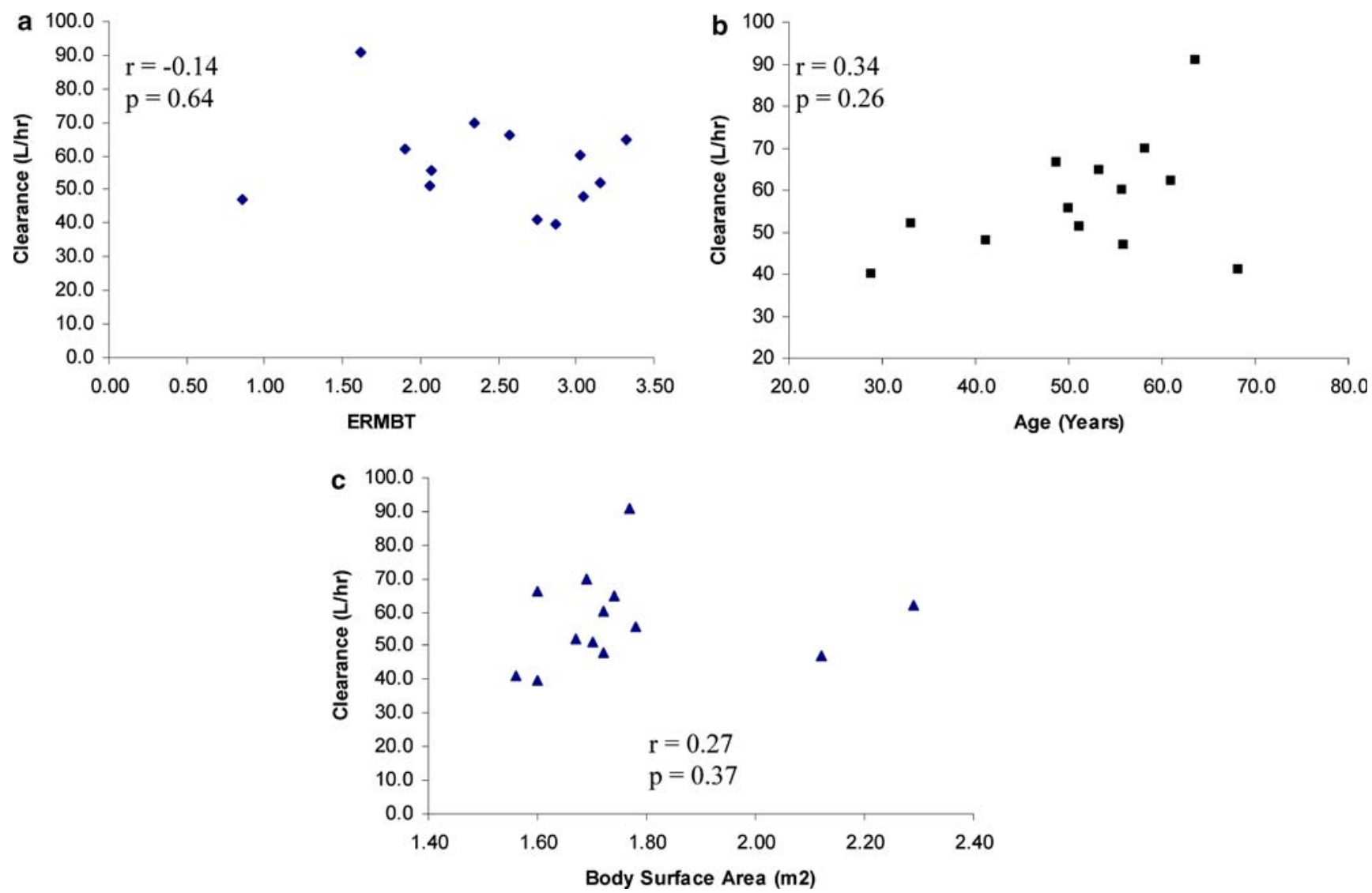

Fig. 1 Lack of relationship of Erythromycin breath test (ERMBT) (a) age or (b) body surface area (c) to vinorelbine clearance

In conclusion, this study demonstrates that a nonBSA-based dosing scheme of capecitabine and vinorelbine is safe and efficacious. Based on these data, we recommend future studies with capecitabine and/or vinorelbine to compare the safety and efficacy of flat-dosed versus BSA-dosed treatment. We cannot determine from this Phase I study whether this combi- nation therapy is more effective than single-agent sequential vinorelbine or capecitabine, and a randomized Phase III study would have to be performed in order to make this treatment a standard recommendation [1] If vinorelbine is ever developed as an oral formulation, further study of this combination therapy is clearly indicated.
Fig. 2 Volume of distribution of vinorelbine is unrelated to body surface area (BSA)

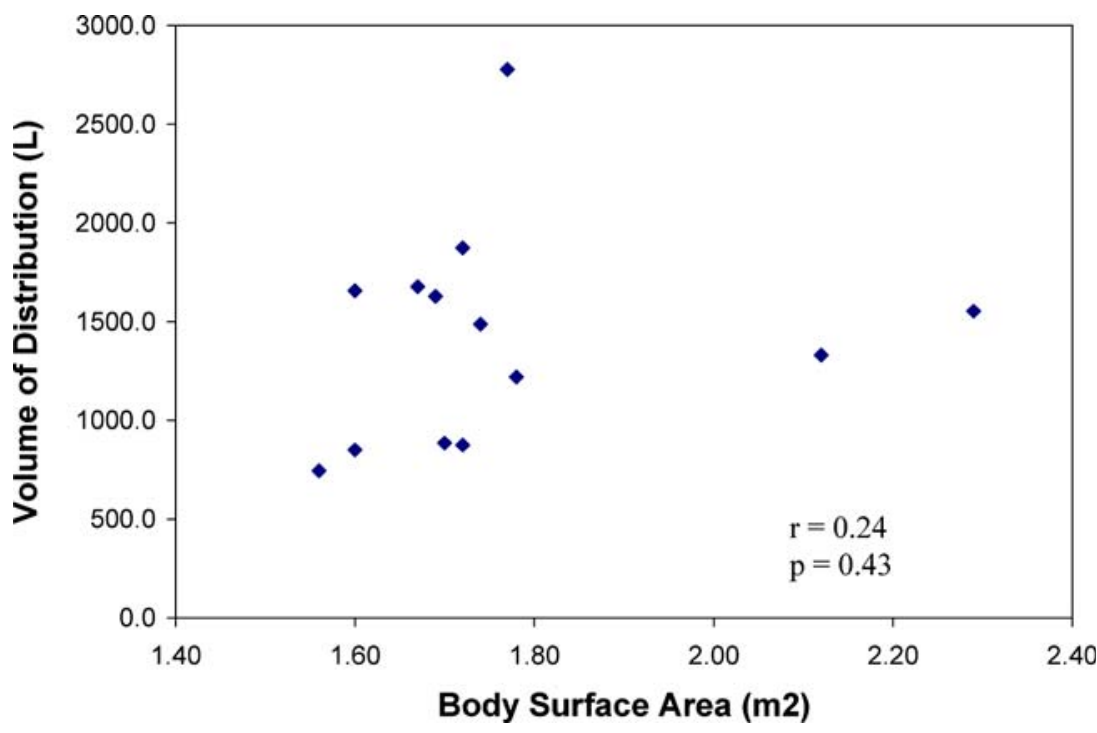




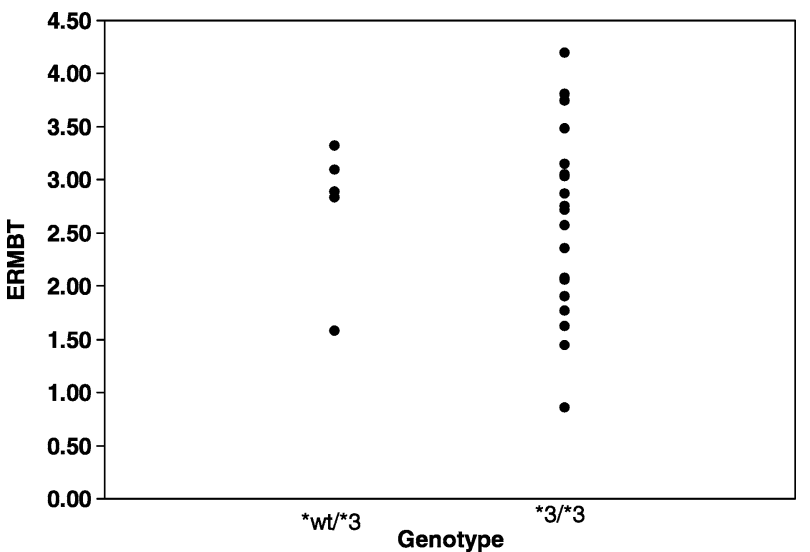

Fig. 3 ERMBT results in the heterozygous and homozygous mutant genotypes seen

Acknowlegements This research was supported (in part) by the National Institutes of Health through the University of Michigan's Cancer Center Support Grant (5 P30 CA46592) and National Institutes of General Medical Sciences grant GM61373 (UO1). Additional support was provided by GlaxoSmithKline, the Fashion Footwear Association of New York/QVC Presents Shoes on Sale ${ }^{\mathrm{TM}}$, and the University of Michigan General Clinical Research Center Grant M01 RR000042. We would like to acknowledge the contribution of A. Benjamin Suttle, Ph.D., Clinical Pharmacology and Discovery Medicine, GlaxoSmithKline, Research Triangle Park, North Carolina, for the pharmacokinetic analysis. Special thanks to Janet Tarolli for her assistance in preparing this manuscript.

\section{References}

1. Baker LH, Vaughn CB, Al-Sarraf M, Reed ML,Vaitkevicius VK (1974) Evaluation of combination vs. sequential cytotoxic chemotherapy in the treatment of advanced breast cancer. Cancer 33:513-518

2. Baker SD, Verweij J, Rowinsky EK, Donehower RC, Schellens JHM, Grochow LB,Sparreboom A (2002) Role of body surface area in dosing of investigational anticancer agents in adults, 1991-2001. JNCI Cancer Spect 94:1883-1888

3. Blum JL, Jones SE, Buzdar AU, LoRusso PM, Kuter I, Vogel C, Osterwalder B, Burger HU, Brown CS, Griffin T (1999) Multicenter phase II study of capecitabine in paclitaxelrefractory metastatic breast cancer. Journal of Clinical Oncology 17:485-493

4. Cassidy J, Twelves C, Cameron D, Steward W, O’Byrne K, Jodrell DI, Baken L, Goggin T, Jones D, Roos B, Bush E, Wedidekamm E, Reigner B (1999) Bioequivalence to two tablet formulations of capecitabine and exploration of age, gender, body surface area, and creatinine clearance as factors influencing systemic exposure in cancer patients. Cancer Chemother \& Pharmacol 44:453-460

5. Goh BC, Lee SC, Wang LZ, Fan L, Guo JY, Lamba J, Schuetz E, Lim R, Lim HL, Ong AB,Lee HS (2002) Explaining interindividual variability of docetaxel pharmacokinetics and pharmacodynamics in Asians through phenotyping and genotyping strategies. J Clin Oncol 20:3683-3690

6. Hess D, Thurlimann B, Pagani O, Aebi S, Rauch D, Ballabeni P, Rufener B, Castiglione-Gertsch M, Goldhirsch A, Swiss Group of Clinical Cancer Research (2004) Capecitabine and vinorelbine in elderly patients ( $>$ or $=65$ years) with metastatic breast cancer: a phase I trial (SAKK 25/99). Ann Oncol 15:1760-1765

7. Hirth J, Watkins PB, Strawderman M, Schott A, Bruno R, Baker LH (2000) The effect of an individual's cytochrome
CYP3A4 activity on docetaxel clearance. Clin Cancer Res 6:1255-1258

8. Hustert E, Haberl M, Burk O, Wolbold R, He YQ, Klein K, Nuessler AC, Neuhaus P, Klattig J, Eiselt R, Koch I, Zibat A, Brockmoller J, Halpert JR, Zanger UM,Wojnowski L (2001) The genetic determinants of the CYP3A5 polymorphism. Pharmacogenetics 11:773-779

9. Jin Y, Desta Z, Stearns V, Ward B, Ho H, Lee KH, Skaar T, Storniolo AM, Li L, Araba A, Blanchard R, Nguyen A, Ullmer L, Hayden J, Lemler S, Weinshilboum RM, Rae JM, Hayes DF,Flockhart DA (2005) CYP2D6 genotype, antidepressant use, and tamoxifen metabolism during adjuvant breast cancer treatment. J Natl Cancer Inst 97:30-39

10. Kajita J, Kuwabara T, Kobayashi H,Kobayashi S (2000) CYP3A4 is mainly responsibile for the metabolism of a new vinca alkaloid, vinorelbine, in human liver microsomes. Drug Metab Dispos 28:1121-1127

11. Kuehl P, Zhang J, Lin Y, Lamba J, Assem M, Schuetz J, Watkins PB, Daly A, Wrighton SA, Hall SD, Maurel P, Relling M, Brimer C, Yasuda K, Venkataramanan R, Strom S, Thummel K, Boguski MS,Schuetz E (2001) Sequence diversity in CYP3A promoters and characterization of the genetic basis of polymorphic CYP3A5 expression. Nat Genet 27:383-391

12. Lamba JK, Lin YS, Schuetz EG,Thummel KE (2002) Genetic contribution to variable human CYP3A-mediated metabolism. Adv Drug Deliv Rev 54:1271-1294

13. Leveque D,Jehl F (1996) Clinical pharmacokinetics of vinorelbine. Clin Pharmacokinet 31:184-197

14. Lorusso V, Crucitta E, Silvestris N, Guida M, Misino A, Latorre A,De Lena M (2003) A phase I study of capecitabine in combination with vinorelbine in advanced breast cancer. Clin Breast Cancer 4:138-141

15. Marquet P, Lachatre G, Debord J, Eichler B, Bonnaud F, Nicot G (1992) Pharmacokinetics of vinorelbine in man. Eur J Clin Pharmacol 42:545-547

16. Miles D, von Minckwitz G,Seidman AD (2002) Combination versus sequential single-agent therapy in metastatic breas cancer. Oncologist 7(suppl 6):13-19

17. Min DI, Ellingrod VL, Marsh S,McLeod H (2004) CYP3A5 polymorphism and the ethnic differences in cyclosporine pharmacokinetics in healthy subjects. Ther Drug Monit 26:524-528

18. O'Shaughnessy J, Miles D, Vukelja S, Moiseyenko V, Ayoub JP, Cervantes G, Fumoleau P, Jones S, Lui WY, Mauriac L, Twelves C, Van Hazel G, Verma S,Leonard R (2002) Superior survival with capecitabine plus docetaxel combination therapy in anthracycline-pretreated patients with advanced breast cancer: phase III trial results. J Clin Oncol 20:2812-2823

19. Oshaughnessy JA, Blum J, Moiseyenko V, Jones SE, Miles D, Bell D, Rosso R, Mauriac L, Osterwalder B, Burger HU,Laws S (2001) Randomized, open-label, phase II trial of oral capecitabine (Xeloda) vs, a reference arm of intravenous CMF (cyclophosphamide, methotrexate and 5-fluorouracil) as firstline therapy for advanced/metastatic breast cancer. Ann Oncol 12:1247-1254

20. Ratain MJ (1998) Body-surface area as a basis for dosing of anticancer agents: science, myth, or habit? J Clin Oncol 16:2297-2298

21. Reigner B, Blesch K,Weidekamm E (2001) Clinical pharmacokinetics of capecitabine. Clin Pharmacokinet 40:85-104

22. Sawyer M,Ratain MJ (2001) Body surface area as a determinant of pharmacokinetics and drug dosing. Invest New Drugs 19:171-177

23. Sledge GW, Neuberg D, Bernardo P, Ingle JN, Martino S, Rowinsky EK,Wood WC (2003) Phase III trial of doxorubicin, paclitaxel, and the combination of doxorubicin and paclitaxel as front-line chemotherapy for metastatic breast cancer: an intergroup trial (E1193). J Clin Oncol 21:588-592

24. Smorenburg CH, Sparreboom A, Bontenbal M, Stoter G Nooter K,Verweij J (2003) Randomized cross-over evaluation of body-surface area-based dosing versus flat-fixed dosing of paclitaxel.[see comment]. J Clin Oncol 21:197-202 
25. VanHeugen J, DeGraeve J, Zorza G, Puozzo C (2001) New sensitive liquid chromatography method coupled with tandem mass spectrometric detection for the clinical analysis of vinorelbine and its metabolites in blood, plasma, urine and faeces. $\mathbf{J}$ Chromatogr A 926:11-20

26. Wargin WA,Lucas VS (1994) The clinical pharmacokinetics of vinorelbine (Navelbine). Semin in Oncol 21:21-27

27. Watkins PB (1994) Noninvasive tests of CYP3A enzymes. Pharmacogenetics 4:171-184
28. Welt A, von Minckwitz G, Oberhoff C, Borquez D, Schleucher R, Loibl S, Harstrick A, Kaufmann M, Seeber S, Vanhoefer U (2005) Phase I/II study of capecitabine and vinorelbine in pretreated patients with metastatic breast cancer. Ann Oncol 16:64-69

29. Wolner E, Domanig E Jr, Elkadi A, Helmer F, Romer P (1968) On a simple relation between blood volume and body surface area. Z Kreislaufforsch 57(1):79-84 